\title{
INTEGRATION OF FLEXIBLE KEYPAD INTO CLOTHING
}

\author{
Inese Parkova ${ }^{1}$, Aleksandrs Vališevskis ${ }^{2}$, \\ Andrejs Kašurins ${ }^{1}$, Ausma Viḷumsone ${ }^{1}$
}

1- Rigas Technical University, Institute of Textile Materials Technologies and Design

Azenes 14, Riga, LV 1048, Latvia

E-mail: inese.parkova@rtu.lv; aleksandrs.valisevskis@rtu.lv; ausma.vilumsone@rtu.lv

2- Rigas Technical University

Division of Mathematical Support of Transport Systems Control

Lomonosova 1/V, Riga, LV 1019, Latvia; e-mail: andrejs.kasurins@ @rtu.lv

\begin{abstract}
The aim of this paper is to consider data input methods and technologies related to information input into electronic systems that would be suitable for smart garments. An overview of recent developments in the area of flexible switches is provided, describing processes used to fabricate these connections and highlighting issues and problems associated with it. Available soft button / keypad products are considered and keypad construction methods are analyzed. This study resulted in the creation of a flexible textile keypad prototype with row-and-column addressable structure and with breaking point technology underneath button design.
\end{abstract}

Keywords: flexible keypad, smart garment, electro-textile interface

\section{Introduction}

Smart clothing is linked to the information and communication infrastructures and provides quiet service to humans by perceiving the environment and at the same time by providing the information generated in personal areas such as health, emotions, and locations of person to the environment. To carry out these functions, all the information systems are equipped with input and output functions [1].

Sensors or switches are used for input in smart clothing; they determine conditions of the surrounding environment (for example, temperature or humidity sensor) or operate and control the system (for example, system ON/OFF switch, volume control buttons). To keep wearing feeling as satisfactory as possible, it is preferable to replace data input mechanical buttons with flexible switches and connections. The aim of this paper is to consider data input methods and technologies related to information input into system that would be suitable for smart garments. As a result of this study, a prototype of input interface is developed.

\section{Materials and methods}

During the last ten years micro-system technology has not only focused on the size of the components but also on their flexibility. Electrotextiles represent enormous potential in creating a new generation of flexible, conformable and multifunctional textile structures for many electrical and electronic systems. Achieving flexible electrical switching is an important part of developing integrated circuits [2]. This chapter provides an overview of recent developments in the area of flexible switching, describing processes used to fabricate these connections and highlighting issues and problems associated with it.

\section{Flexible switches}

Switch is a mechanism that is used to open or close circuit in mechanical or electrical way. Flexible switches can be made using different materials and technologies. Soft circuits can be created using operating principles of conventional switches, replacing hard materials with textile materials to provide flexibility, besides that traditional clothing fasteners can be used for electrical connections. Several unconventional examples of flexible switching and connections designed with textile materials or clothing accessories are shown in Table 1. 
Table 1.

Examples of flexible switches

\begin{tabular}{|c|c|c|}
\hline Title & Material & Description \\
\hline $\begin{array}{l}\text { Soft press } \\
\text { button / keypad }\end{array}$ & $\begin{array}{l}\text { Textile, } \\
\text { conductive } \\
\text { material, } \\
\text { insulating material }\end{array}$ & $\begin{array}{l}\text { Press buttons introduce a breaking point somewhere } \\
\text { in the circuit. A braking point is area where it is } \\
\text { possible to reconnect the circuit, in result we can } \\
\text { determine if the soft pushbutton is active (pushed) or } \\
\text { not [3]. For keypad the same principle is used but } \\
\text { with more complicated configuration. Usually two } \\
\text { layers of conductive material are separated with a } \\
\text { perforated insulator in this design. }\end{array}$ \\
\hline $\begin{array}{l}\text { Flexible } \\
\text { capacitive } \\
\text { keypad }\end{array}$ & $\begin{array}{l}\text { Textile, } \\
\text { conductive } \\
\text { material }\end{array}$ & $\begin{array}{l}\text { In a capacitive keyboard, electricity is flowing } \\
\text { through the key matrix at all times. When a key is } \\
\text { pressed, it changes the flow of electricity at that point, } \\
\text { which the keyboard's controller interprets as input. } \\
\text { Though these keyboards are more expensive than } \\
\text { traditional ones, they tend to be more durable [4]. }\end{array}$ \\
\hline $\begin{array}{l}\text { Knitted } \\
\text { pressure } \\
\text { sensitive button }\end{array}$ & $\begin{array}{l}\text { Acrylic fibers, } \\
\text { stainless steel }\end{array}$ & $\begin{array}{l}\text { Knitted pressure sensitive fabric made of three layers. } \\
\text { Two layers of stainless steel are separated by one } \\
\text { layer of acrylic fibers. When pressed, the two external } \\
\text { layers touch, an electrical circuit is closed allowing } \\
\text { current flow [5]. }\end{array}$ \\
\hline $\begin{array}{l}\text { Conductive } \\
\text { hook and loop } \\
\text { connection }\end{array}$ & $\begin{array}{l}\text { Nylon tape with } \\
\text { silver coating }\end{array}$ & $\begin{array}{l}\text { Nylon hook and loop tape, both sides are coated with } \\
\text { silver. Good for making switches or connections that } \\
\text { might need to be opened and closed [6]. }\end{array}$ \\
\hline Zipper switch & $\begin{array}{l}\text { Plastic or metal } \\
\text { zipper }\end{array}$ & $\begin{array}{l}\text { To turn a zipper into a switch, the two upper and } \\
\text { lower teeth opposite each other can be sewn with } \\
\text { conductive thread. A conductive path from each } \\
\text { zipper tooth can be continued to the rest of the circuit. } \\
\text { When the zipper is closed or opened with the slides, } \\
\text { two opposing teeth connect, closing the circuit. Each } \\
\text { set of teeth on opposing rows of the zipper can also } \\
\text { individually addressed to create a switch [7]. }\end{array}$ \\
\hline $\begin{array}{l}\text { Connection of } \\
\text { traditional } \\
\text { metal fastener } \\
\text { for clothing }\end{array}$ & Metal & $\begin{array}{l}\text { Large part of clothing accessories are made from } \\
\text { metal, hence they are conductive and suitable for } \\
\text { creating electronic connections. These parts can be } \\
\text { used for connections: hook and eye, buttons, snaps, } \\
\text { poppers, magnets, grommets etc. Good for making } \\
\text { switches or connections that might need to be opened } \\
\text { and closed. }\end{array}$ \\
\hline
\end{tabular}

Commonly it is provided that in smart garments wearer may input information to the devices, for example, to control which sensor to use. The most common input interface for this purpose involves buttons or keyboards because simple button interfaces are easy to learn, implement and use with few errors. As the complexity of wearable electronic devices increases, however, the need for more complex interfaces arises [8]. Further in the paper available soft button / keypad products are considered, other methods and types of keypads are analyzed, in the conclusion to this study a flexible keypad prototype is constructed. 


\section{Available soft button / keypad products}

Introduction of soft buttons at the end of the previous century was one step further for smart clothing development - hard plastic material contacts were replaced with rubber and foam material combination, which later led to further development of electronic industry, for example, to the design of soft electric boards. Currently there are several companies in the market producing flexible switch panels for smart garment, some of them are shown in Table 2.

Table 2.

Available soft button / keypad products

\begin{tabular}{|c|c|c|}
\hline Company & Technology & Application \\
\hline Peratech & $\begin{array}{l}\text { The company produces flexible switch } \\
\text { panels using Quantum Tunnelling } \\
\text { Composite (QTC) technology. QTC is } \\
\text { composite material made from } \\
\text { conductive filler particles combined with } \\
\text { an elastomeric binder. QTC can change } \\
\text { from an electrical insulator to a metal- } \\
\text { like conductor. While in an unstressed } \\
\text { state the QTC material is a near-perfect } \\
\text { insulator; with any form of deformation } \\
\text { the material starts to conduct [9]. }\end{array}$ & $\begin{array}{l}\text { QTC can be used to produce low } \\
\text { profile, low cost, pressure activated } \\
\text { switches or sensors that display } \\
\text { variable resistance with applied } \\
\text { force and return to a quiescent state } \\
\text { when the force is removed [11]. } \\
\text { Switching panels provided for } \\
\text { integration into clothing, soft } \\
\text { furniture, walls, toys and other soft } \\
\text { surfaces. Flexible switches were } \\
\text { used in MP3 and iPod jackets. }\end{array}$ \\
\hline Eleksen & $\begin{array}{l}\text { Switches are made using ElekTex } \\
\text { technology, which is based on QTC } \\
\text { electro-conductive fabric. ElekTex is a } \\
\text { laminate of multiple fabric layers, which } \\
\text { are arranged to form a resistive touchpad. } \\
\text { The sensor is contact activated - } \\
\text { positional X and Y values are generated } \\
\text { together with a low resolution pressure } \\
\text { measurement }(\mathrm{Z})[13] .\end{array}$ & $\begin{array}{l}\text { Widely used in different fields from } \\
\text { entertainment to military field. } \\
\text { Touchpad can be provided in } \\
\text { different interfaces: keypad, MP3 } \\
\text { player interface, volume regulation } \\
\text { slider etc [8]. Examples: iPod jacket } \\
\text { grooveRider, Zegna iJacket, } \\
\text { Message bag, rolled up keyboards. }\end{array}$ \\
\hline Fibretronic & $\begin{array}{l}\text { The company produces textile and } \\
\text { polymer based switches and keypads. } \\
\text { Each of the buttons has a click response } \\
\text { to ensure that the user can feel that the } \\
\text { button has been activated when pressed. } \\
\text { This keypad cannot be false triggered by } \\
\text { body movement and so does not require a } \\
\text { keypad locking function [14]. }\end{array}$ & $\begin{array}{l}\text { The company supplies textile } \\
\text { switches, flexible keypads, iPod, } \\
\text { iPhone controls, mobile phone } \\
\text { interfaces, garment heating systems, } \\
\text { fabric sensors and wearable lighting } \\
\text { systems. Products designed } \\
\text { specifically for integration in } \\
\text { clothing and soft goods [15]. } \\
\text { Example: RedWire DLX jeans. }\end{array}$ \\
\hline
\end{tabular}

\section{Flexible fabric interface}

Electro-textile interface is indispensable in producing smart clothing, but it is very difficult to integrate the electronic products and fabric products because their manufacturing processes and their physical properties differ greatly. In addition to these differences specialists of the textile industry and electronics industry must break out of stereotypical way of thinking and connect these two vastly isolated fields [1]. In order to replace bulky wires and solid breadboards it is necessary to search for such solutions as flexible textile interfaces. 


\section{Flexible circuit substrates}

Conventional printed circuit boards (PCB), which consist of multi-layered structured organic material and conductive elements made using photolithography or electron beam lithography method, are solid and bulky. In order to form flexible circuit board, printing of circuit patterns is carried out on polymeric substrates such as film. Fabric based circuits potentially offer additional benefits of higher flexibility in bending and shear, higher tear resistance, as well as better fatigue resistance in case of repeated deformation [2]. An ideal textile sensor would be fabric that can generate electricity or change the flow of electric current in its reaction to external stimulation. Unfortunately, with the currently available technology it is almost impossible to obtain woven fabrics or compounds possessing such functions. Hence it is necessary to consider combining electronic components with fabric materials to the extent that would not hinder the user's activities [1]. Used methods for textile platform construction are described below.

Embroidery. Conductive threads are often sewed or embroidered along the circuit paths [1]. One of the advantages of this process of fabric circuit formation is that the conductive threads can be embroidered in any shape on the fabric irrespective of the constituent yarn path in fabric [2]. Embroidery can be used for example in textile keypad creating - it could be made on a single layer of fabric. This process enables one to specify precisely the circuit layout and stitch pattern in a computer-aided design (CAD) environment, from which any number of items can be sewn under machine control [16]. In Fig.1.A a keypad is shown that was embroidered with conductive threads on denim and was used in MIT Media Lab project 'Musical Jacket'. During sewing conductive threads encounter various levels of stresses and friction - this requires an embroidery thread to have relatively high strength and flexibility because stress can lead to yarn breaks. Discontinuities are not desirable in fabric circuits joints or splices to fix the discontinuities in sewn conductor lines may lead to undesirable additional impedance [2]. In the case of the narrow band, short circuits in between wires are another weakness of the embroidery method [1].

Printing. Conductive ink printing produces a circuit, using a method similar to the PCB manufacturing process, which theoretically can be the simplest and easiest way to make a circuit. It is also easy to make the mass production system. The circuit can be made by silkscreening or by using digital textile printer. The biggest problem is the procurement of highly conductive ink [1]. Conductive ink can be used for low-powered control and secondary elements that don't conduct high current. It is unadvisable to use it in connections where high safety and reliability is necessary. It is not recommended to apply printed circuits technology on elastic fabric - stretching can result in breaking of printed conductive tracks. Printed circuit pattern is shown in Fig.1.B.

Weaving and knitting. Much attention has been paid to the conductive textiles with woven in metal yarns. However, once a conductive fabric is woven, the electrical tracks and tailoring are restricted in weft or wrap direction [1]. Narrow woven technology was shown to be one of the most promising textile manufacturing methods because the fabric structure allows for easy integration of conductive and optical materials [17]. The narrow band is similar to the flat electric cable; it is woven with several threads of conductive fiber placed in parallel. In general metal yarn or thread coated with metallic particles is used as a conductor. To prevent possible short circuits in between wires, threads are generally coated with insulating material. Narrow knitted band is shown in Fig.1.C. 


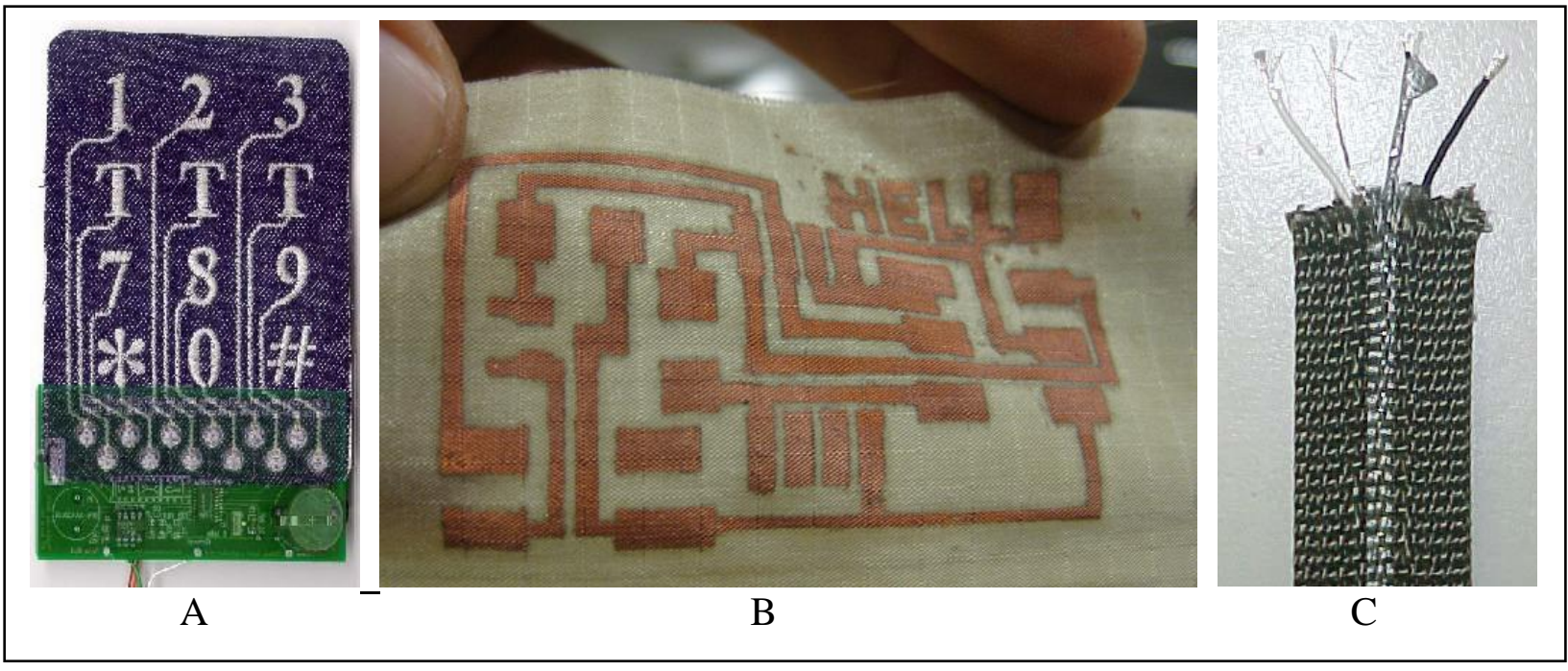

Fig.1. A - Musical Jacket keypad; B - printed circuit pattern; C - narrow knitted band

Coating. Textile substrates with conductive polymer or metal coatings are potential candidates of electronic textile, having good characteristics such as good conductivity, flexibility, free tailoring and easy sewing. One of the drawbacks of this method is the loss of electric conductivity when washed. Tin/copper coated fabric is shown in Fig.2.A and B.

Sew on / stick on. Textile transmission lines can be suggested as one of the applications of surface-conductive fabrics. The surface of the coated fabric is conductive in all directions so that it can be cut into any shape and in any direction. The fabric pieces can be directly sewn onto clothing, thus dangling wires or cables often seen inside today's smart wear might disappear [18]. Flexible circuit made of conductive fabric stuck on elastic non-conductive surface is shown in Fig. 2.C.

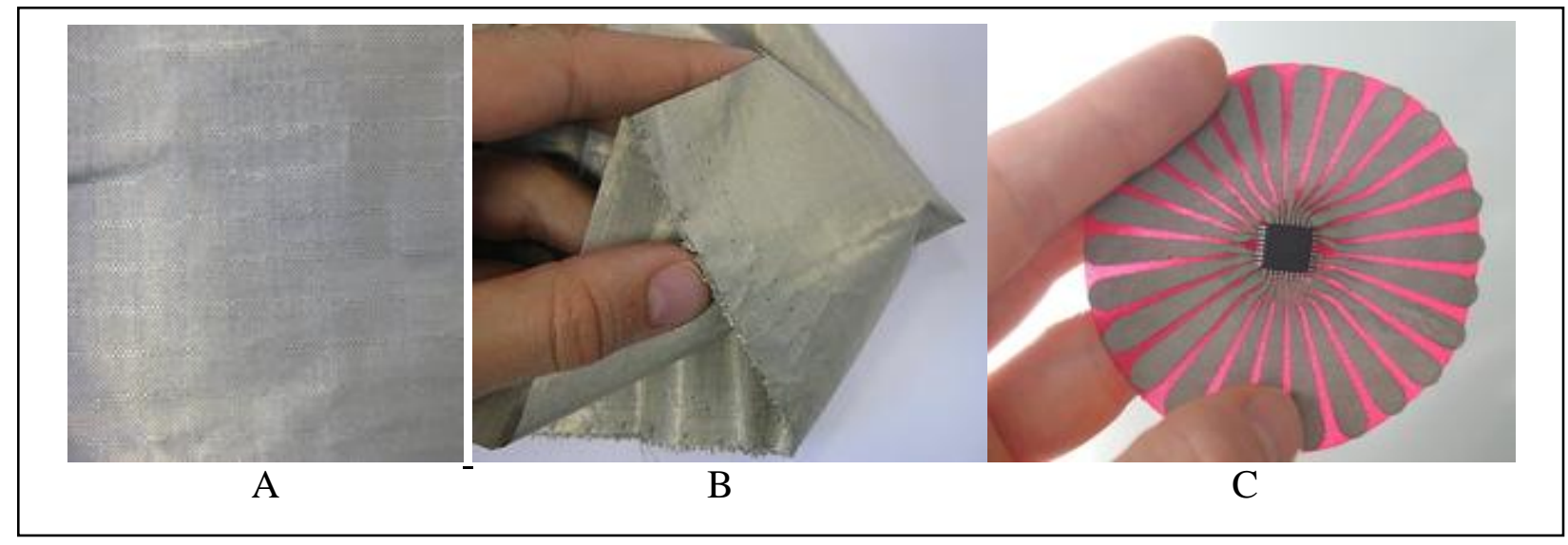

Fig. 2. A, B - Tin/copper coated fabric; C-Conductive fabric stuck to soft citcuit

\section{Insulation}

In most applications it is important to insulate the conductive traces. For stretchy traces this requires a stretchy insulator. Suitable insulators are: stretchy fabric glue, puffy fabric paint, extra layers of fabric, silicone layer. It is important to take into consideration that coating of insulating layer adds thickness and rigidity, therefore it is necessary to choose insulators that would make coating layer as thin as possible, would be safe enough and at the same time would reduce system flexibility as little as possible. 


\section{Arrangement and applications of flexible keypad}

Flexible keypads can be integrated in the majority of smart clothing and accessories where data input and/or control is necessary from wearer's side. Examples are MP3 clothing, iPod jackets, GPS jacket, Message bag etc. Control interfaces should be close to the parts of body concerned, for example in MP3 jacket earphones are located in a collar or a bonnet, a microphone is in a collar and a keyboard is applied to the sleeve of a jacket. Some variants of keypad arrangements are shown in Fig.3.

The ergonomic adaptation of all these control interfaces to clothing is also very important. In contrast to certain miniaturized communication devices, clothing has a greater surface area, which enables it to offer more functionality. For example, the small keyboard of a mobile phone becomes much more readable when transposed to the surface of a piece of clothing that is three times larger [19].

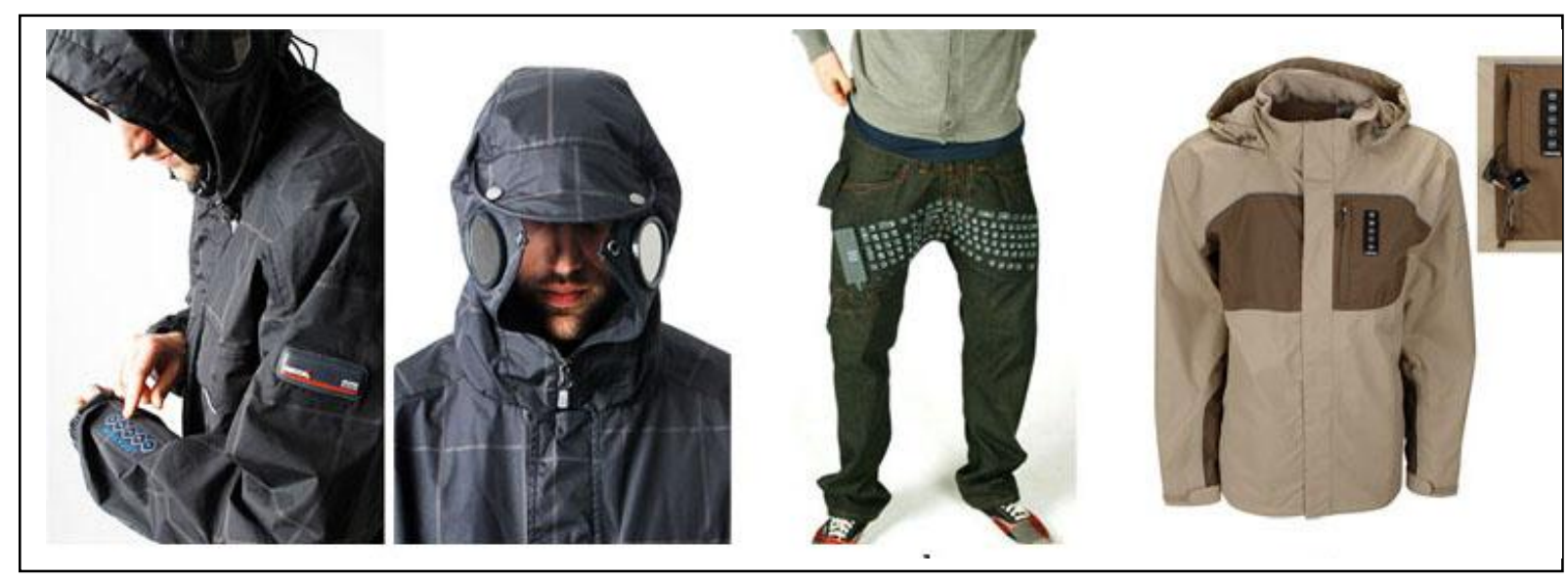

Fig. 3. Variants of keypad arrangements

\section{Flexible keypad prototype}

Flexible fabric keypad prototype was created with row-and-column addressable structure and with breaking point technology underneath button design.

Interfaces. First step in button/keypad design is choosing flexible conductive material for buttons contact surfaces. Copper is a good conductor, thus thin copper film was chosen for the first prototype. Soft keypad interface is a mobile phone's keyboard with buttons embroidered on cotton fabric.

Operation principle. Conductive elements of keypad construction are thin $1 \mathrm{~cm}$ wide copper strips that are placed vertically and horizontally. Each intersection of strips corresponds to a button. Insulating intermediate layer is located between the vertical and the horizontal strips foam plastic material is chosen for this purpose and it is perforated at strip intersections. By pressing a button, strips of vertical and horizontal layers are connected through isolating layer holes and the circuit is closed. When button is not active, strips disjoin and circuit opens.

Insulation layer fixing. Foam plastic material is chosen as insulation layer for the first prototype. To align all layers precisely without displacement it is necessary to fix them. For layer fixing fusing method was used. Adhesive netting was applied as fusing material, which traditionally is used in clothing production process. Adhesive netting was placed between two layers and fixed with iron (temperature of iron was about $150{ }^{\circ} \mathrm{C}$ ). To one side of insulating layer vertically positioned copper strips were fixed and to the other side of insulating layer horizontally positioned copper strips were fixed. 


\section{Results and discussion}

This paper summarizes literature about different approaches towards design of flexible switches, besides that processes and materials used in soft switches and connections were described and advantages and drawbacks were highlighted. The acquired information was used to analyze the available materials and technologies and a flexible keypad prototype was made. Keypad is shown in Fig.4. It proves that the chosen method can be applied practically: all keys are functioning correctly and are located at a convenient distance. However several ways of improving this design are possible. For example, it is preferable to put in use different materials to reduce rigidity of multilayered keypad construction, it applies both to conductive materials and to the insulator.

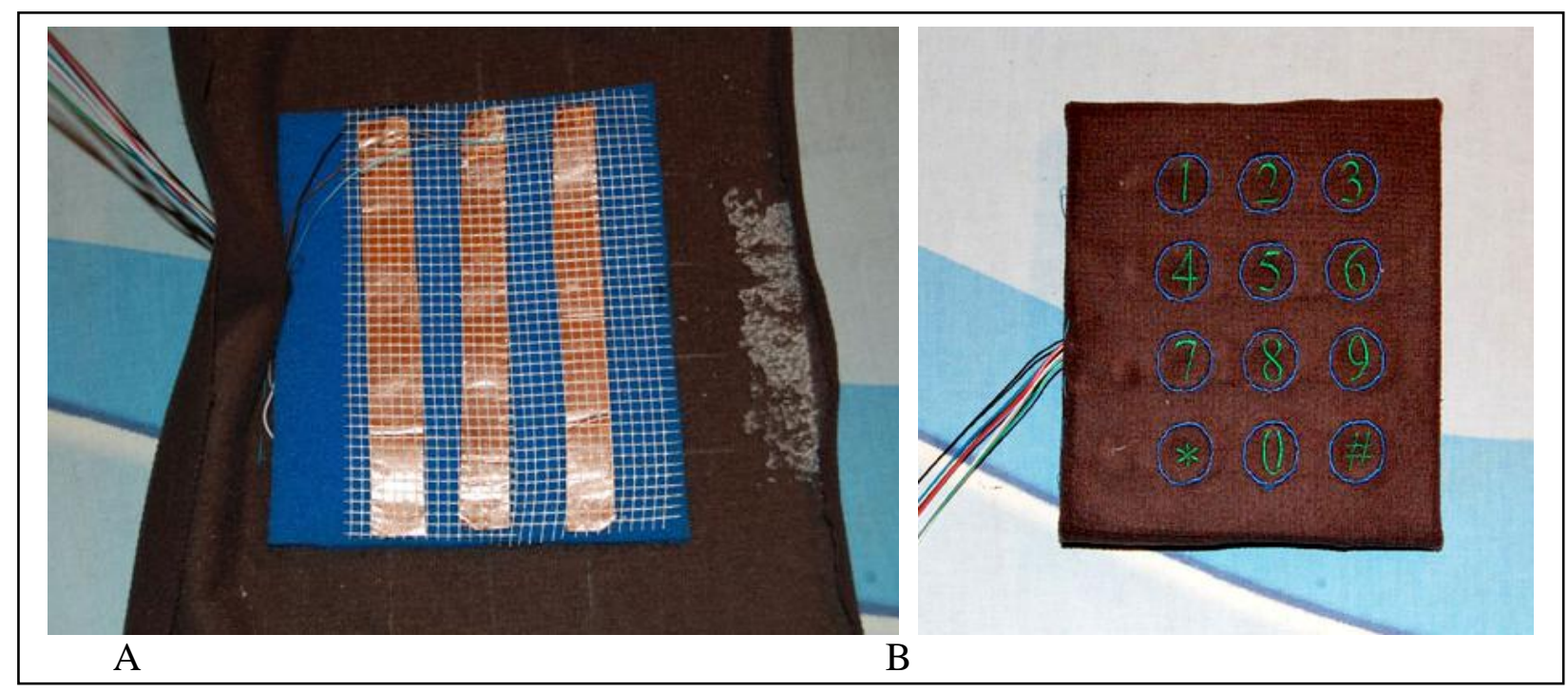

Fig.4. Flexible keypad prototype. A - construction of keypad; B - embroidered interface

During further research in flexible keypad design we plan to replace copper foil with more flexible material - conductive fabric or copper net. On the other hand, foam plastic insulator can be replaced with softer foam latex; this will reduce keypad thickness and will increase its flexibility.

Another prospective direction of research are capacitive touch-sensitive panels, which do not require any physical deformation, they are especially suitable for using in textile materials and smart garments.

Textile-based input devices constitute one of the most important challenges in electronic textiles area, since soft buttons integrated into clothing must be flexible and easy to operate. In this paper data input methods and technologies are considered, which are suitable for smart garments. An overview of recent developments in the area of flexible buttons is provided, describing steps needed to make these buttons and highlighting issues and problems associated with it. Several unconventional examples of flexible switching and connections designed from textile materials or clothing furniture are described. Available soft button / keypad products are considered and other methods and types of keypads are analyzed. Some flexible circuit substrates for textile platform construction are described - embroidery, printing, weaving, knitting, coating, sewing, gluing. Suitable insulators are provided and arrangement and applications of flexible keypad are discussed. As a result of this study a flexible fabric keypad prototype was created with row-and-column addressable structure and with breaking point technology underneath button design. 


\section{Acknowledgment}

This work has been supported by the European Social Fund within the project "Support for the implementation of doctoral studies at Riga Technical University" and European Social Fund co-financed project "Establishment of interdisciplinary research groups for a new functional properties of smart textiles development and integrating in innovative products".

\section{References}

1. Gilsoo Cho. Smart Clothing. Technology and applications. Taylor and Francis Group and CRC Press LLC, 2010, pp $9091-92979595$

2. H.R.Mattila. Intelligent textiles and clothing. Woodhead Publishing Limited and CRC Press LLC, Cambridge, England, 2006, pp 239, 242240241

3. T. Olsson, D. Gaetano, J. Odhner, S. Wiklund. Open Softwear - fashionable prototyping and wearable computing using the Arduino, 2008, pp 41

4. Computer accessories / Internet - http://curiosity.discovery.com/question/what-is-a-capacitive-keyboard

5. The EMF Safety Superstore / Internet - http://www.lessemf.com/kits.html

6. Conductive Velcro / Internet - http://www.kobakant.at/DIY/?p=362

7. S. Pakhchyan. Fashioning Technolgy. Published by Make:Books. Italy, 2008, pp 64

8. X. Tao. Wearable Electronics and Photonics. Woodhead Publishing Limited and CRC Press LLC, Cambridge, England, 2005, pp 3

9. QTC material / Internet - http://www.peratech.com/qtcmaterial.php

10. Soft Switching for Electronic Textiles / Internet - http://www.textileweb.com/article.mvc/Soft-Switchingfor-Electronic-Textiles-0001

11. QTC technology / Internet - http://www.peratech.com/qtctechnology.php

12. Eleksen / Intenet - http://www.eleksen.com/?page=aboutus/index.php

13. ElekTex technology / Internet - http://www.eleksen.com/?page=technology/elektex.php

14. Lite Keypad (KP2-4G) / Internet - http://fibretronic.com/connectedwear/KP24G

15. Fibretronic Ltd / Internet - http://fibretronic.com/

16. E.R.Post, M.Orth, P.R.Russo, N.Gershenfeld. E-broidery: design and fabrication of textile-based computing. IBM Systems Journal, 39 (3\&4), 2000, pp 840-860.

17. C.A. Winterhalter, J. Teverovsky, W. Horowitz, V. Sharma, K. Lee. Wearable Electro-Textiles For Battlefield Awareness. ADM001736, Proceedings for the Army Science Conference (24th), Orlando, Florida, 2005.

18. J. Cho, J.Moon, M.Sung, K.Jeong, G.Cho. Design and evaluation of textile based signal transmission lines and keypads for smart wear. Human-Computer Interaction. Interaction Platforms and Techniques. Lecture Notes in Computer Science, 2007, Volume 4551/2007

19. Communication Apparel and Optical Fibre Fabric Display / Internet - http://people.brunel.ac.uk/ dap/ smart3.html 